Cadernos do IL o Cadernos do IL e Cadernos do IL e Cadernos do IL e Cadernos do IL o Cadernos do IL

\title{
SAUSSURE E O ESTRUTURALISMO: RETOMANDO ALGUNS PONTOS FUNDAMENTAIS DA TEORIA SAUSSURIANA
}

\author{
Alessandra da Silveira Bez* \\ Carla de Aquino**
}

\begin{abstract}
RESUMO: Este artigo tem como objetivo apresentar alguns conceitos pioneiros fundados por Saussure e que são utilizados em diversas áreas da ciência Linguística. Através da leitura do Curso de Linguística Geral (Curso) temos os pilares teóricos do linguista genebrino: língua, fala, relação, valor. Procurar-seá discutir também como as fontes manuscritas podem complementá-los. Utilizaremos os leitores de Saussure como fontes de informações adicionais, sempre tomando a leitura do Curso como indispensável e esclarecedora. Além disso, discutiremos como os conceitos fundados pelo mestre serviram de base para um estudo fonológico estruturalista.
\end{abstract}

PALAVRAS-CHAVE: Estruturalismo - Estudo fonológico - Relação

RESUMÉ: Cet article a le but de présenter quelques concepts pionniers fondés par Saussure et qui sont utilisés en surfaces différentes de la science linguistique. Á travers la lecture du Cours de Linguistique Générale (CLG) nous avons les piliers théoriques du linguiste genevois: langue, parole, relation, valeur. Nous discuterons aussi comment les sources manuscrites peuvent les complémenter. Nous recourrons aux lecteurs de Saussure comme sources de reinsegnements additionnels, toujours prenant la lecture du Cours comme indispensable et éclairée. De plus, nous argumenterons comment les concepts fondés par le maître furent la base d'un étude phonologique structuraliste.

MOTS-CLÉS: Structuralisme - Étude phonologique - Relation

\section{INTRODUÇÃO}

Um dos pontos chave a serem discutidos a respeito da importância do trabalho realizado por Saussure é que, embora tenha fundado o estudo de uma ciência com matéria e objeto bem definidos, de acordo com conceitos positivistas de ciência, o fez

\footnotetext{
* Doutoranda em Linguística pelo Programa de Pós-Graduação da PUCRS, bolsista CNPq. Atualmente em estágio de doutoramento no exterior na École des Hautes Études en Sciences Sociales - Paris, França, com bolsa concedida pela CAPES. alesbez@yahoo.com

** Doutoranda em Linguística pelo Programa de Pós-Graduação da PUCRS, bolsista CNPq. Atualmente em estágio de doutoramento no exterior na University of California - Berkeley, EUA, com bolsa concedida pela CAPES. carla.deaquino@hotmail.com
} 
Cadernos do IL o Cadernos do IL e Cadernos do IL e Cadernos do IL e Cadernos do IL e Cadernos do IL

pelas palavras de outros, que organizaram seus cursos e elaboraram uma obra póstuma. Muitas das críticas voltadas ao professor não cabem a ele, mas a uma organização e, portanto, interpretação de suas ideias. Saussure não foi um positivista, assim como não foi um estruturalista, mas o Curso foi publicado em um cenário positivista, do qual carrega algumas características e teve uma leitura estruturalista subsequente.

Milner (2003) traz à tona as questões de identidade do texto e dos problemas de edição do Curso. A partir do que foram organizadas as ideias de Saussure? Das notas de dois ou três alunos? De amigos que não assistiram aos cursos ministrados por ele? Além disso, para que se criasse o que o autor chama de "um todo orgânico" foram juntados fragmentos de diferentes datas, de diferentes cursos e organizados na mesma edição. Por outro lado, embora Milner reconheça que em alguns momentos a formulação escolhida para a obra não tenha sido a melhor possível, tenha sido ao mesmo tempo bem e mal compreendida, não há como negar que o Curso é uma obra de circulação dentro de uma cultura e representa um marco nos estudos linguísticos. Como pontos fundamentais da teoria desenvolvida por Saussure, Milner destaca as noções de signo e de relação - o signo como conceito primitivo do Curso - e a ideia de valor que permite a existência do signo.

Simon Bouquet (2009), um pouco mais radical, trata o Curso como um "pseudoSaussure", e o toma como autor ilegítimo das ideias editadas na obra. Bouquet cita diversos trechos modificados pelos editores quanto à organização do Curso e outros criados por eles para esclarecimento de conceitos que acabam contradizendo as ideias de Saussure. Alguns fatos destacados são a ambiguidade da palavra 'signo', a inseparabilidade das faces do signo que não é mantida no Curso, e os três fenômenos descritos pelo termo valor que é reduzido ao valor in absentia no Curso. $\mathrm{O}$ autor acredita que as aulas dos cursos são deformadas, deturpadas e que o acesso ao Saussure "autêntico" só se dá através dos Escritos.

De qualquer forma, Saussure cria, através do Curso e das fontes mais tarde descobertas, um modelo epistemológico. Sua reflexão não cria uma metodologia de trabalho, mas discute questões fundamentais da filosofia da linguagem.

Normand (2009a, p.23) oferece uma leitura histórico-crítica que busca "estabelecer em que medida o CLG funda a lingüística enquanto ciência, ou seja, introduz uma mudança radical em relação aos discursos anteriores e contemporâneos".

Além dessa questão, algumas das temáticas muito abordadas com relação ao Curso e às Fontes é o caráter fragmentário dos textos e um tipo de escrita considerado aforístico. Acerca disso, Jäger (2003, p.205) aponta que "o aspecto fragmentário dos textos saussurianos não são a expressão de uma redação não alcançada ou mesmo falta de definição na intenção do autor". Ou seja, embora a estrutura dos textos encontrados tenha tais características, o autor acredita que não podemos tomá-la como uma marca de

Cadernos do IL. Porto Alegre, n. ${ }^{\circ} 42$, junho de 2011. p. 5-17. 


\section{Cadernos do IL $\odot$ Cadernos do IL e Cadernos do IL $\odot$ Cadernos do IL e Cadernos do IL e Cadernos do IL}

incompletude de pensamento. Para Jäger, Saussure tinha sim uma ideia consistente a respeito da filosofia da linguagem e das mudanças que considerava necessárias na forma de pensá-la e estudá-la. Segundo o autor, o estilo aforístico "corresponde a um estilo e a uma escritura conscientemente escolhidos para examinar o que Saussure nomeia 'pontos delicados' da teoria da linguagem" (ibid., p.205).

Normand (2006) discorre sobre o que chama de "brancos" nos manuscritos de Saussure. Assim como Jäger ao falar dos aforismos, a autora defende que os brancos são marcas de presença e que têm sentido no texto de Saussure, diferentemente do que defendem Godel, Engler e Starobinsky. Com base na forma do texto, na pontuação utilizada e até mesmo no tamanho dos espaços deixados em branco, Normand acredita que Saussure sabia o que queria dizer, mas, por escrúpulo teórico ou terminológico, acabou deixando no texto apenas as lacunas.

Há diferentes posicionamentos frente ao Curso editado em 1916. Há leitores que acreditam que o Curso foi um excelente trabalho de organização de um material a que não teríamos acesso se tal tarefa não tivesse sido realizada por Bally e Sechehaye. Há aqueles que pensam que o trabalho dos organizadores foi insuficiente para que tenhamos acesso à teoria proposta por Saussure e, portanto, acreditam ser necessária a leitura dos escritos encontrados posteriormente para termos uma visão mais geral do pensamento de Saussure. E há, ainda, leitores mais radicais que pensam ser o Curso uma distorção das ideias do mestre e que sugerem que apenas poderemos ter acesso ao "verdadeiro" Saussure através das Fontes.

Trabant (2005) duvida da possibilidade de se abandonar o Curso e de buscar as ideias do "verdadeiro" Saussure nos manuscritos. O autor questiona se os manuscritos fazem sentido neles e por eles mesmos, uma vez que são de difícil compreensão e são organizados com base no Curso. Além disso, defender que eles sejam a fonte do verdadeiro é desprezar que a própria organização dos escritos já se constitui como uma interpretação.

No que concerne tal discussão, Normand (2007) acredita que o estudo das fontes desconhecidas pelos editores do Curso de 1916 podem sim tornar sua leitura mais rica, mais complexa e completa. Entretanto, a autora defende que isso não a "invalida" e que não há como definirmos (julgarmos) o que seja 'verdadeiro' ou 'falso' em termos das ideias do mestre.

Como afirma Normand (2009b, p.18), "Saussure está condenado a ser acessível apenas pela floresta de comentários e pelo quebra-cabeça de fragmentos reencontrados".

Nas seções seguintes, abordaremos alguns dos conceitos básicos e mais difundidos da teoria de Saussure.

Cadernos do IL. Porto Alegre, n. ${ }^{\circ}$ 42, junho de 2011. p. 5-17. 
Cadernos do IL o Cadernos do IL e Cadernos do IL e Cadernos do IL e Cadernos do IL e Cadernos do IL DEFINIÇÃO DO OBJETO E DO PAPEL DO LINGUISTA

A ciência linguística, diferente de todas as outras, tem um objeto que é de certa forma partilhado com as outras ciências. As demais ciências falam de seus objetos, anteriormente definidos, fazendo uso da língua. No caso da linguística, usa-se a língua para falar dela mesma. Difícil tarefa essa do linguista.

O objeto da linguística é o estudo da língua como sistema, recorte da matéria criado pelo ponto de vista e, portanto, há tantos objetos quantos forem os pontos de vista. Dessa forma, como afirma Gadet (1996) não há objeto a priori, ou anterior à análise. Ou seja, diferentemente das outras ciências que elegem o seu objeto, já existente e disponível para a análise, na ciência linguística, o objeto só se cria quando a linguagem é recortada e colocada em funcionamento pelos indivíduos. Portanto, é o sujeito que cria o objeto.

Normand (2009a) afirma que parece haver, no decorrer da definição do objeto da ciência linguística, uma ligação com o empírico. Tal fato é indicado por questionamentos de Saussure sobre a existência das unidades linguísticas. A autora ainda ressalta que as dificuldades apresentadas por Saussure em encontrar termos para definições no vocabulário utilizado na época acabaram gerando certa incoerência com sua orientação de pensamento.

O capítulo mencionado deixa claro que o método empírico não é suficiente para a caracterização e classificação das unidades da língua, uma vez que o real não é um critério na língua, segundo a autora. A partir do princípio de funcionamento da língua por oposições, Saussure cria um procedimento racionalista da análise do concreto, mas devemos questionar o que é real $n a$ língua, e não introduzido do exterior. Em suma, o Curso busca a definição do objeto da ciência, mas refuta a análise empirista.

A língua como sistema proposta por Saussure se constitui como um tipo de sistema completamente diferente dos demais. Conforme Normand (2009b, p.38), um dos grandes objetivos do curso é 'mostrar' aos linguistas o que eles fazem e levá-los a refletir sobre o seu 'objeto'. Segundo a autora, ele introduz nos estudos da linguagem a noção de ponto de vista na especificação do objeto - o todo da língua não é papel do linguista - e uma nova concepção da língua, diferente do que se conhecia antes através dos estudos de gramática comparada, que buscava descrever historicamente as línguas sem tocar nas questões maiores de linguagem. Além disso, introduzem-se os diferentes pontos de vista do locutor - o simples usuário da língua - que conhece apenas aquele momento da língua que fala e que possui um saber inconsciente, e do conhecedor - o linguista, a quem cabe "se situar na língua, como um locutor qualquer" (NORMAND, 2009b, p. 47) para explicar o mecanismo do sistema que estuda. 
Cadernos do IL o Cadernos do IL e Cadernos do IL e Cadernos do IL e Cadernos do IL e Cadernos do IL

Saussure deixa claro em seus cursos que acredita ser necessário que o linguista tome consciência do que faz, da sua tarefa e de que há um grande problema com os métodos anteriores de estudo da linguagem, como a linguística histórica e a gramática comparativa, pelo fato de que eram estudos exaustivos de evolução que não tinham um objetivo claro, segundo ele: pura comparação sem conclusões.

A diferença entre o papel do linguista e o do falante está exatamente em enxergar como se dá a relação entre os signos e a realidade. Benveniste $(1988$, p.57) aponta para esse fato quando afirma que "para o falante há, entre a língua e a realidade, adequação completa: o signo encobre e comanda a realidade; ele é essa realidade". O autor acrescenta que "Na verdade, o prisma do sujeito e do linguista são tão diferentes a esse respeito que a afirmação do linguista quanto ao arbitrário das designações não refuta o sentimento contrário dos falantes".

\section{SIGNO E TEORIA DO VALOR}

O signo é uma unidade de dupla face que tem valor dentro da língua. Essa entidade é composta, então, por um conceito e uma imagem acústica, tratados no Curso como significado e significante, respectivamente. A busca por uma precisão ou adequação terminológica perseguiu Saussure durante a escrita de suas notas de cursos. De Mauro (1972, nota 137) discute as 'definições provisórias' dadas pelo professor genebrino a significado e significante - conceito e imagem acústica - e na nota 140 a escolha não completamente satisfatória pelo termo 'signo'. Observa-se uma grande variedade de tentativas com o uso de termos como símbolo, signo, sema, vocábulo, etc. De Mauro afirma nessa última nota que Saussure tem "dificuldade de encontrar os termos que designam o signo em sua integralidade, sem deslizamento equívoco para um só elemento das duas faces".

Saussure (2004) ainda trata a face do significante como 'signo', que se une a um significado. Essa variedade de termos utilizados na busca por uma referência mais adequada gerou algumas confusões interpretativas.

Pelo princípio da semiologia apresentada no CLG, as unidades da língua só podem ser estudadas em termos de valor. $\mathrm{O}$ valor não é o conceito, mas a significação do signo em sua totalidade no sistema. A propriedade do termo não se mantém fora do uso, ela se estabelece no dado, na relação, na diferença.

Uma imagem muito conhecida na representação do signo na língua é a figura oval com duas partes, a superior - onde está o significado - e a inferior - onde está o significante. Tal imagem é conhecida e também controversa, uma vez que no Curso

Cadernos do IL. Porto Alegre, n. ${ }^{\circ}$ 42, junho de 2011. p. 5-17. 
Cadernos do IL o Cadernos do IL e Cadernos do IL e Cadernos do IL e Cadernos do IL o Cadernos do IL

utiliza-se uma gravura de uma árvore para representar o significado. O significado não é um objeto, mas uma ideia; o significante não é som, mas uma imagem acústica.

A relação que se estabelece entre essas duas partes do signo é arbitrária, assim como o é a relação que se estabelece entre o signo como um todo e qualquer entidade no mundo. Saussure busca distanciar-se da realidade e afirma que a língua não é uma representação dela. $\mathrm{O}$ objeto da linguística apenas pode ser a língua já constituída como sistema.

Segundo Benveniste (1988, p.55), a relação que se dá entre o signo e a realidade é arbitrária, mas a relação existente entre o significado e o significante é necessária. Podemos interpretar o laço entre as duas partes do signo como necessário para que ele exista.

Benveniste afirma que "o arbitrário é que um signo, e não outro, se aplica a determinado elemento da realidade, mas não outro" (p.56). O autor diz ainda que "o arbitrário só existe aqui em relação com o fenômeno ou o objeto material e não intervém na constituição própria do signo" (p.57).

Tullio de Mauro (1972, nota 132) discute o capítulo sobre o signo linguístico e a "manipulação" do material proveniente dos cursos de Saussure. O autor afirma que as figuras utilizadas para ilustração do conceito de signo não são todas de Saussure. A última imagem, de uma árvore, foi acrescentada pelos editores do Curso, e mesmo com a intenção de facilitar o entendimento de conceitos, eles acabaram contradizendo o que afirmava Saussure, de que o significado não era a coisa, o elemento no mundo, e que o significante não era a palavra, o vocábulo.

Outra observação de De Mauro (1972) a respeito da edição dessa aula é a de que desaparece no Curso o termo 'radicalmente', que define a arbitrariedade do vínculo entre significante e significado, além da utilização de terminologias provenientes de diferentes aulas, cursos e datas pelos editores, como a própria definição de significado e significante. De Mauro acredita que, com o rigor terminológico apresentado por Saussure, o termo (radicalmente) não seria empregado simplesmente com efeito de ênfase.

\section{LÍNGUA E FALA}

A língua é um conjunto de saberes linguísticos que possuem os falantes e que os possibilita fazer julgamentos de identidades e diferenças. Esses conhecimentos estão no "espírito" dos falantes, na "consciência" do coletivo, e é isso o que faz da língua um fato social.

Cadernos do IL. Porto Alegre, n. ${ }^{\circ}$ 42, junho de 2011. p. 5-17. 


\section{Cadernos do IL $\odot$ Cadernos do IL e Cadernos do IL $\odot$ Cadernos do IL e Cadernos do IL e Cadernos do IL}

Segundo o Curso (SAUSSURE, 1975, p.27), a língua "trata-se de um tesouro depositado pela prática da fala em todos os indivíduos pertencentes à mesma comunidade". Ela não está completa em nenhum indivíduo e só o pode ser no todo, na massa falante, embora seja constituída apenas através da fala.

Podemos observar que as linhas metodológicas de análise que separam a língua da fala são muito tênues, uma vez que fenomenologicamente elas não podem ser separadas, uma não existe sem a outra.

Sem dúvida, esses dois objetos são estreitamente ligados e se implicam mutuamente; a língua é necessária para que a fala seja inteligível e produza todos os seus efeitos; mas esta é necessária para que a língua se estabeleça; historicamente o fato da fala vem sempre antes. Como se imaginaria associar uma ideia a uma imagem verbal se não se surpreendesse de início esta associação num ato de fala? (-SAUSSURE, 1975, p.27)

Assim sendo, Depecker (2009) define um fato linguístico como um recorte feito pelo falante. $\mathrm{O}$ falante não somente cria a língua, como também julga o que faz ou não parte dela e tem a capacidade de mudá-la, embora nunca o faça sozinho. Para que se crie uma unidade, é necessário que se atribua sentido, e novamente quem o faz é o falante, é ele quem dá valor à língua.

Conforme tais observações, é o valor que une língua e fala. São os valores em presença que produzem os valores em ausência. A língua só se constitui porque existe a fala, o concreto, e é a existência da língua que possibilita a fala.

De acordo com Bouquet (2000, p.257-267), existem dois tipos de valor estabelecido nas relações a partir da bipartição metodológica entre língua e fala: o valor em ausência (interno ou sistêmico) e o valor em presença, sintagmático, criado pelas relações no dado, conforme veremos em seguida.

\section{EIXO ASSOCIATIVO E EIXO SINTAGMÁTICO}

Há dois tipos de relações possíveis, as associativas ou in absentia e as sintagmáticas ou in presentia. As primeiras tratam-se de possibilidades existentes na língua e no conhecimento ou consciência do falante. Esses agrupamentos se formam de maneira diferente, seja por características morfológicas, seja pela semelhança entre os significantes ou entre os significados. Assim, são relações de ordens diferentes que regem elementos pertencentes à gramática da língua. As relações sintagmáticas, por sua vez, representam as escolhas dos falantes, aquilo que foi recortado dentro das alternativas disponíveis. Podemos dizer que enquanto as primeiras estão disponíveis na

Cadernos do IL. Porto Alegre, n. ${ }^{\circ}$ 42, junho de 2011. p. 5-17. 


\section{Cadernos do IL o Cadernos do IL o Cadernos do IL e Cadernos do IL o Cadernos do IL o Cadernos do IL}

língua, as últimas pertencem à fala. Nesse último caso, observa-se a relação de sucessão, ordem e o valor estabelecido no uso.

Gadet (1996, p.91) refere-se a esses dois eixos como "sistema virtual", o da língua, e "sistema realizado", o da fala. A autora ainda acrescenta que no sistema realizado, tanto no caso das palavras como das frases, "a organização sintagmática manifesta uma solidariedade entre os elementos: as unidades maiores são constituídas de unidades menores, em um espaço de solidariedade recíproca" (p.92).

Esses dois eixos ou duas esferas entram em funcionamento no mecanismo linguístico e se completam. Quando colocamos a língua em funcionamento, quando temos uma ideia, não chamamos apenas um termo na nossa consciência, mas todo o sistema para julgamento e seleção. Fica claro, então, que o sistema somente pode ser colocado em funcionamento pelo indivíduo falante e isso só é possível porque ele abriga a gramática da língua que o permite fazer esses julgamentos.

\section{SINCRONIA E DIACRONIA}

Saussure não rompe com a linguística diacrônica. Ele separa os estudos sincrônicos dos diacrônicos como método de trabalho, mas não deixa de discutir a diacronia na língua. A realidade sincrônica não exclui a diacrônica e vice-versa. Enquanto a diacronia trata de mudanças isoladas que repercutem no sistema e o afetam como um todo, a sincronia estuda valores e relações coexistentes dentro de um momento da diacronia. Ou seja, a diacronia aborda fatos de ordem acidental e particular e é sempre composta por sincronias.

Diante da impossibilidade de estudar o sistema como um todo, é necessário que sejam feitos recortes. No CLG fica claro que é necessário que sejam estudadas sincronias para possibilitar o estudo da diacronia, portanto é a isso que se propõe o Curso.

No Curso trata-se a sincronia como linguística estática. O termo estático dá uma noção de estado e nada tem a ver com parado. A língua não é apresentada como um sistema fechado e imutável, mas que se movimenta e evolui.

\section{MUDANÇA E PRESERVAÇÃo}

As noções de mudança e de preservação estão intrinsecamente ligadas à fala e à língua. Enquanto uma garante que o sistema seja fixo, socialmente estabelecido, a outra permite que ele seja colocado em funcionamento e que os indivíduos possam criar com

Cadernos do IL. Porto Alegre, n. ${ }^{\circ}$ 42, junho de 2011. p. 5-17. 


\section{Cadernos do IL $\odot$ Cadernos do IL e Cadernos do IL $\odot$ Cadernos do IL e Cadernos do IL e Cadernos do IL}

base no seu conhecimento. O caráter arbitrário do signo evita a mudança e o alcance dela, quando ocorre, é muito pequeno. Por outro lado, ela existe e é inegável do ponto de vista da circulação. Uma vez que a língua entra em funcionamento, perde-se o controle do que pode ser feito pelos seus falantes.

A analogia é um exemplo de mecanismo que coloca a língua - a gramática da língua - em funcionamento e a modifica. Ao mesmo tempo em que ela modifica a língua, o faz com base em um conhecimento sobre ela. São novas relações que se estabelecem com apoio em formas existentes na língua. Ela é forma de mudança e de preservação no sistema. Nesse ponto se encontram língua e fala, sincronia e diacronia.

\section{SENTIDO}

De acordo com a semiologia fundada por Saussure, o essencial é o sentido, não o caráter fônico. Para o Curso, nada é abstrato na língua, tudo é real porque tudo tem sentido. A semiologia estuda "a vida dos signos no seio da vida social" (SAUSSURE, 1975, p.24).

Normand (1990) desenvolve a tese de que o CLG, a teoria saussuriana do valor, desenvolve um "programa de uma semântica linguística". Os dois questionamentos que norteiam o artigo são: "que semântica Saussure autorizou?" e "as proposições de Saussure apresentam um fechamento ou uma abertura para uma teoria da significação?". Para a autora, o CLG é uma teoria da significação e isso é possível na medida em que Saussure desenvolve um novo tipo de semântica, um processo teorica e metodologicamente novo. É apenas do ponto de vista semiológico que se pode abordar a língua e ela deixa de ser um todo heteróclito. Segundo Normand (1990, p.5), "A linguística, assim restrita, (...) se ocupará apenas de saber como funciona um sistema linguístico, qualquer que ele seja, como, em suma, ele significa e quais características permitem que ele faça isso". A autora afirma que, embora a língua seja forma e não substância, isso não quer dizer que ela seja forma desprovida de sentido, "uma diferença formal possui valor linguístico à medida que está ligada a uma diferença de sentido" (p.7). Dessa forma, a língua se constitui de diferenças formais de oposição e de combinação que geram sentido.

Conforme explicitado por Normand no artigo mencionado, o princípio semiológico em Saussure compreende relações de origem sintagmática e paradigmática para que se realizem as combinações necessárias à língua. O programa construído por Saussure não se resume à semântica lógica, não existem leis e a sintaxe não pode ser analisada separadamente da semântica. O sistema deve funcionar como um todo em que 


\title{
Cadernos do IL o Cadernos do IL o Cadernos do IL e Cadernos do IL o Cadernos do IL o Cadernos do IL
}

tudo gera sentido. A semântica saussuriana se estabelece na reflexão sobre o valor, do qual a significação é apenas uma parte.

\section{BASES PARA UM ESTUDO FONOLÓGICO ESTRUTURALISTA}

Como afirma Benveniste (1988), Saussure foi considerado o 'precursor' do estruturalismo e o é em certo ponto, uma vez que foi ele quem estabeleceu em seus estudos a noção de termos dependentes em um todo que é solidário. Entretanto, o 'precursor' do estruturalismo moderno nunca usou o termo 'estrutura', ele preocupou-se em descrever o funcionamento da língua como um 'sistema'.

Saussure difunde a noção de sistema através do estudo das vogais do indoeuropeu. $\mathrm{O}$ autor chega à conclusão de que não se pode estudar apenas uma ou duas vogais da língua sem tratar de todo o sistema vocálico, já que os elementos são complementares em um todo que se auto-regula.

Benveniste acrescenta que,

\begin{abstract}
a noção da língua como sistema havia muito que era admitida pelos que haviam recebido o ensinamento de Saussure, primeiro em gramática comparada, depois em linguística geral. Se se acrescentam estes dois outros princípios, igualmente saussurianos, de que a língua é forma, não substância, e de que as unidades da língua não podem definir-se a não ser pelas suas relações, indicam-se os fundamentos da doutrina que iria, alguns anos mais tarde, pôr em evidência a estrutura dos sistemas linguísticos (BENVENISTE, 1988, p.100).
\end{abstract}

Representantes dos estudos subsequentes a Saussure foram os linguistas russos, Roman Jakobson, S. Karcevsky e N. Trubetzkoy, todos eles estudando os sistemas fonológicos e as estruturas que os compõem. Além desses autores, quando utilizamos o termo 'estrutura', remetemos também ao Círculo Linguístico de Praga, que amparou os trabalhos desses estruturalistas.

Dentro da fonologia podemos encontrar diversos pontos de convergência com os estudos saussurianos. O primeiro deles é a prioridade aos estudos sincrônicos da língua. A linguística histórica perde espaço para as descrições sincrônicas das línguas. O segundo ponto é uma semente que foi também plantada pelo mestre e resultou na diferenciação de campos de atuação para a fonética e a fonologia, a primeira delas responsável pelos estudos de dados de fala, individuais, e a última pelos fatos distintivos e descrição dos sistemas das línguas, compartilhados no social.

Cadernos do IL. Porto Alegre, n. ${ }^{\circ} 42$, junho de 2011. p. 5-17. 


\title{
Cadernos do IL o Cadernos do IL o Cadernos do IL e Cadernos do IL o Cadernos do IL o Cadernos do IL
}

Troubetzkoy (1970, p.95) em sua obra Principes de Phonologie, dedicada a Roman Jakobson, define o objetivo do estudo que propõe:

\begin{abstract}
notre tache dans le presént chapitre n'est pas de systématiser les possibilités qu'a l'appareil phonatoire de produire des sons, mais de passer systématiquement em revue les particularités phoniques effectivement utilisées dans les différentes langues du monde pour distinguer des significations. (grifonosso)
\end{abstract}

De acordo com o trecho supracitado, podemos observar que o que define um fonema na língua é a propriedade de distinção de sentido, assim como pela definição de Saussure um signo dentro do sistema é o que tem valor, sentido. Podemos acrescentar ainda que os estudos fonológicos se baseiam em um método que se origina na teoria Saussuriana, o das oposições.

Conforme o dicionário de lingüística da Oxford, de P. H. Mathews (1997, p.279), o sistema fonológico de uma língua é, seguindo a terminologia da escola de Praga, "uma estrutura de oposições entre fonemas que são definidos pelos traços fonéticos que os distinguem".

No Brasil o principal representante do estruturalismo na linguística foi Mattoso Câmara, que introduz um novo discurso nos estudos da linguagem, a abordagem sincrônica do sistema ou 'estrutura' da língua. Mattoso Câmara teve seu trabalho amplamente influenciado por Jakobson e pela linguística norte-americana (Círculo Lingüístico de Nova Iorque) e foi o primeiro linguista a propor uma análise estrutural do Português do Brasil.

Esse trabalho inaugural da fonologia estruturalista no Brasil se baseou em dados do Português falado no Rio de Janeiro e apresentou um sistema fonêmico de 26 unidades, sendo elas 19 sons consonantais e 7 vocálicos. Conforme o modelo estruturalista, o autor analisou e descreveu os sons do PB (Português Brasileiro) em seu papel distintivo. Os testes de comutação (substituição) foram aplicados e os fonemas foram estudados em distribuição livre ou complementar, seguindo a ideia saussuriana do sistema de termos dependentes e solidários.

Altman (2004, p.148-149) ressalta que

Embora Mattoso estivesse perfeitamente ciente de que os dois quadros estruturalistas de trabalho, os assim chamados europeu e norte-americano, pudessem ser distinguidos um do outro sob vários aspectos, ele não via diferenças substanciais entre o funcionalismo inaugurado por Trubetzkoy e o estruturalismo proposto por Sapir. Ao contrário, na sua leitura, as proposições

Cadernos do IL. Porto Alegre, n. ${ }^{\circ}$ 42, junho de 2011. p. 5-17. 


\section{Cadernos do IL o Cadernos do IL o Cadernos do IL e Cadernos do IL o Cadernos do IL o Cadernos do IL}

de Saussure, Trubetzkoy, Sapir, Jakobson e Bloomfield não só não eram incompatíveis, como complementavam umas às outras.

Dessa forma, o autor utiliza-se de terminologia advinda das duas correntes em sua descrição.

\section{CONCLUSÃO}

Como podemos observar, em um estudo da teoria da linguagem proposta por Saussure, cria-se uma teia de implicação entre conceitos absolutamente imbricados. Não há como explicar um deles sem fazer referência aos demais e é necessário que se tome toda a teoria com base na noção de relação.

Os questionamentos dentro da ciência linguística se mantêm. Há uma recorrência de questionamentos anteriores a Saussure em sua proposta e verificamos que ainda hoje as dúvidas dos linguistas são as mesmas: questões como o papel do linguista, a importância do sujeito na língua, a organização de um sistema que é ao mesmo tempo individual e partilhado (língua e fala), e outros conceitos importantes.

Neste artigo apresentamos alguns dos questionamentos do mestre genebrino e discutimos o surgimento do estruturalismo e as relações que ele apresenta com a teoria da linguagem proposta por Saussure.

Embora o estruturalismo de Mattoso Câmara tenha sido rapidamente considerado ultrapassado e tenha dado espaço a outras teorias de análise fonológica, o estudo sincrônico, as noções de relação, de oposição, de valor e sentido na língua, e de arbitrariedade, trazidos por Saussure, continuam servindo como base para os estudos em fonologia.

\section{REFERÊNCIAS}

ALTMAN, Cristina. A Conexão Americana: Mattoso Câmara e o Círculo Linguistico de Nova Iorque. DELTA, n.20, especial, 2004, p.129-158.

BENVENISTE, E. Problemas de Linguística Geral I. Pontes, Campinas: 1988.

BOUQUET, Simon. De um pseudo-Saussure aos textos saussurianos originais. Letras e Letras (Revista do Instituto de Letras e Linguística da Universidade Federal de Uberlândia). Vol.25, número1, jan./jun. de 2009. . Introdução à leitura de Saussure. São Paulo: Cultrix, 2000.

Cadernos do IL. Porto Alegre, n. ${ }^{\circ}$ 42, junho de 2011. p. 5-17. 


\section{Cadernos do IL o Cadernos do IL o Cadernos do IL e Cadernos do IL o Cadernos do IL o Cadernos do IL}

DE MAURO, Tullio. Cours de linguistique générale. Édition critique préparée par Tullio de Mauro. Paris: Payot, 1972.

DEPECKER, Loïc. Comprendre Saussure d'après lês manuscrits. Paris: Armand Colin, 2009.

GADET, Françoise. Saussure: une science de la langue. Paris: PUF, 1996.

JÄGER, Ludwig. La pensée épistémologique de F. de Saussure. In: L’Herne: Saussure (Cahier dirige par Simon Bouquet). Paris, Éditions de L'Herne, 2003.

MATHEWS, P. H. Concise Dictionary of Linguistics. New York: Oxford University Press Inc., 1997.

MILNER, Jean-Claude. Saussure: Retorno a Saussure. In: El periplo structural: figures e paradigma. Amorrortur/Editores, Buenos Aires, 2003.

NORMAND, Claudine. Proposições e notas para uma leitura de F. de Saussure. In: Convite à linguística. São Paulo: Contexto, 2009a. . Saussure. São Paulo: Estação Liberdade, 2009b.

Saussure: une épistémologie de La linguistique. Atas de Colóquio. Séoul, 2007. Les blancs des manuscrits saussuriens. In: Allegro ma non troppo: invitation à

la linguistique. Ophrys, 2006.

SAUSSURE, Ferdinand de. Curso de Linguística Geral. São Paulo: Cultrix, 1975. . Escritos de Linguística Geral. São Paulo: Cultrix, 2004.

TRABANT, Jürgen. Faut-il défendre Saussure contre ses amateurs? Notes item sur l'étymologie saussurienne. In: CHISS, Jean-Louis; DESSONS, Gérad. Langages. Larousse, Paris, n.59, septembre 2005.

TOUBETZKOY, N. S. Principes de Phonologie. Paris: Éditions Klincksieck, 1970.

Cadernos do IL. Porto Alegre, n. ${ }^{\circ}$ 42, junho de 2011. p. 5-17. 